\title{
X-linked intellectual disability, Shashi type
}

INSERM

\section{Source}

INSERM. (1999). Orphanet: an online rare disease and orphan drug data base. $\underline{X \text {-linked }}$ intellectual disability, Shashitype. ORPHA:85286

X-linked intellectual disability, Shashi type is characterised by moderate intellectual deficit, obesity, macroorchidism and a characteristic facies (large ears, a prominent lower lip and puffy eyelids). It has been described in nine boys from two families. Transmission is Xlinked and the causative gene has been localised to the q21.3-q27 region of the $X$ chromosome. 